\title{
LA INCIDENCIA DE LA LIBERTAD RELIGIOSA EN LA RELACIÓN DE TRABAJO DESDE LA PERSPECTIVA DEL TRIBUNAL CONSTITUCIONAL ESPAÑOL
}

\author{
IVÁN ANTONIO RODRIGUEZ CARDO ${ }^{1}$
}

\begin{abstract}
RESUMO: O direito de liberdade religiosa por vezes colide com os outros direitos e deveres que surgem em razão do contrato de trabalho. O empregador, evidentemente, está obrigado a respeitar o credo de seus trabalhadores, mas é possível, de um lado, que o próprio empresário defenda uma determinada ideologia e, de outro, que o trabalhador solicite uma adaptação das condições de trabalho para tornar compatível sua religião com as obrigações laborais.

PALAVRAS-CHAVE: Contrato de Trabalho; Liberdade Religiosa; Professantes de Religião; Empresas Ideológicas; Jurisprudência Constitucional.
\end{abstract}

ABSTRACT: The right to religious freedom sometimes collides with the rights and duties arising from employment contract. Of course, the employer is obliged to respect the beliefs of their workers, but it is possible, firstly, that the employer defend a particular ideology, and, secondly, that the worker must request an adjustment of working conditions to get their creed compatible with job duties. KEYWORDS: Contract of Employment; Religious Freedom; Religious Teachers; Ideological Businesses; Constitutional Case Law.

RESUMEN: El derecho de libertad religiosa colisiona en ocasiones con los derechos y deberes que surgen del contrato de trabajo. Por supuesto, el empleador está obligado a respetar las creencias de sus trabajadores, pero es posible, por un lado, que el propio empresario defienda una determinada ideología, y, por otro, que el trabajador solicite una adaptación de las condiciones de trabajo para hacer compatible su credo con las obligaciones laborales.

PALABRAS CLAVE: Contrato de Trabajo; Libertad Religiosa; Profesores de Religión; Empresas Ideológicas; Jurisprudencia Constitucional.

SUMÁRIO: 1. A repercussão da liberdade religiosa na relação laboral: Catálogo de situações conflituosas no Tribunal Constitucional; 2 . Conteúdo e limites da liberdade religiosa e sua configuração legal; 3 . A modalização dos direitos e deveres laborais nas empresas de tendência de caráter religioso: A STC 5/1981, de 13 de fevereiro, como principal referência; 4 . Valores e princípios que subjazem na jurisprudência constitucional sobre as empresas de tendência religiosa; 5 . A problemática específica dos professantes de religião em centros públicos (STF 38/2007, de 15 de fevereiro);

Artigo recebido em 16.05.2011. Artigo aceito para publicação em 31.05.2011 mediante convite.

${ }^{1}$ Profesor Titular de Universidad Interino (Universidad de Oviedo, España). rodriguezivan@uniovi.es 
6. Valores e princípios que subjazem na jurisprudência constitucional sobre seleção de profissão de religião em centros públicos; 7. A dupla face ativa e passiva da liberdade religiosa; 8. A vertente ativa ou positiva da liberdade religiosa na jurisprudência constitucional (STC 19/1985, de 13 de fevereiro); 9. Valores e princípios que subjazem na jurisprudência constitucional sobre a vertente ativa da liberdade religiosa; 10 . A resposta da jurisdição ordinária à vertente positiva da liberdade religiosa; Referências.

SUMMARY: 1. Religious freedom's repercussion in the labor relationship: Catalog of conflict situations facing the Constitutional Court; 2. Religious freedom's content and limits and its legal configuration; 3 . The modulation of labor rights and duties on companies with a tendency of religious character: STC 5/1981, of February 13 th, as the main reference; 4 . Values and principles which inform the constitutional jurisprudence on companies of religious tendency; 5 . The specific issue of the exercise of religious beliefs in public facilities (STF 38/2007, of February 15th); 6 . Values and principles which inform the constitutional jurisprudence on the choice of religious belief in public facilities; 7 . Religious freedom's dual active/ passive perspective; 8 . The active (positive) perspective of religious freedom in the constitutional jurisprudence (STC 19/1985, of February 13th); 9. Values and principles which inform constitutional jurisprudence on the active perspective of religious freedom; 10. Regular jurisdiction's answer to religious freedom's positive perspective; References.

SUMARIO: 1. La repercusión de la libertad religiosa en la relación laboral: catálogo de situaciones conflictivas ante el Tribunal Constitucional; 2 . Contenido y límites de la libertad religiosa en su configuración legal; 3. La modalización de los derechos y deberes laborales en las empresas de tendencia de carácter religioso: la STC 5/1981, de 13 de febrero, como referente principal; 4 . Valores y principios que subyacen en la jurisprudencia constitucional sobre las empresas de tendencia; 5. La problemática específica de los profesores de religión en centros públicos (STC 38/2007, de 15 de febrero); 6 . Valores y principios que subyacen en la jurisprudencia constitucional sobre selección del profesorado de religión en centros públicos; 7. La doble faceta activa y pasiva de la libertad religiosa. 8. La vertiente activa o positiva de la libertad religiosa en la jurisprudencia constitucional (STC 19/1985, de 13 de febrero); 9. Valores y principios que subyacen en la jurisprudencia constitucional sobre la vertiente activa de la libertad religiosa; 10 . La respuesta de la jurisdicción ordinaria a la vertiente positiva de la libertad religiosa; Breve Reseña Bibliográfica.

\section{LA REPERCUSIÓN DE LA LIBERTAD RELIGIOSA EN LA RELACIÓN LABORAL: CATÁLOGO DE SITUACIONES CONFLICTIVAS ANTE EL TRIBUNAL CONSTITUCIONAL}

La Constitución reconoce una serie de derechos fundamentales, dotados de una especial protección y cuya limitación sólo puede tener lugar por causas justificadas. La celebración de un contrato de trabajo no supone, obviamente, que el trabajador se vea privado de los derechos que le corresponden como persona. No obstante, la incardinación en el círculo rector y de organización del empresario trae como consecuencia que el ejercicio de los derechos fundamentales deba conciliarse con los legítimos intereses empresariales. Entre esos derechos fundamentales se encuentra «la libertad ideológica, religiosa y de culto de los individuos y las comunidades sin más limitación, en sus manifestaciones, que la necesaria para el mantenimiento del orden público protegido por la ley» (art. 16 CE). El alcance de ese derecho a la libertad 
religiosa se perfila en la Ley Orgánica 7/1980, de 5 de julio, de Libertad Religiosa.

El reconocimiento constitucional de la libertad religiosa como derecho fundamental hace inevitable que surjan conflictos centrados en la delimitación precisa de sus contornos, con el fin de encontrar mecanismos e instrumentos que permitan dar una respuesta satisfactoria a las situaciones de colisión de la libertad religiosa con los derechos o intereses legítimos de otras personas, que por supuesto merecen una adecuada tutela.

Un repaso a la jurisprudencia constitucional demuestra que, de una $u$ otra forma, la libertad religiosa ha sido el origen, o ha estado involucrada, en aproximadamente cinco decenas de supuestos, de índole muy diverso. La casuística es heterogénea, ya que los litigios pueden versar sobre la relación entre los tribunales eclesiásticos y los civiles (SSTC 1/1981, de 26 de enero, $66 / 1982$, de 12 noviembre, y 93/1983, de 8 noviembre), sobre el reconocimiento y ejercicio del derecho en las Fuerzas Armadas (SSTC 24/1982, de 13 mayo, 616/1984, de 31 octubre, y 177/1996, de 11 noviembre), y en los Cuerpos y Fuerzas de Seguridad del Estado (STC 101/2004, de 2 junio), sobre la discriminación derivada del prejuicio (STC 141/2000, de 29 mayo), sobre la enseñanza obligatoria de la religión en centros públicos (ATC 359/1985, de 29 mayo, y STC 155/1997, de 29 septiembre), sobre el significado de la aconfesionalidad del Estado (SSTC 180/1986, de 21 febrero, y 340/1993, de 16 noviembre), sobre el derecho de los padres a elegir la educación de los hijos (SSTC 260/1994, de 3 octubre, 382/1996, de 18 diciembre, y 133/2010 de 2 diciembre), sobre el trato fiscal a las confesiones religiosas (ATC 480/1989, de 2 octubre), sobre su invocación con el fin de elegir un determinado tratamiento médico compatible con las creencias religiosas (SSTC 166/1996, de 28 octubre, y 154/2002, de 18 julio), así como sobre facetas de su contenido con repercusión indirecta en otros derechos y libertades, como sucede con la objeción de conciencia en relación, por ejemplo, con el aborto (STC 53/1985, de 11 abril).

Junto a esta clase de litigios, la mayoría de ellos naturales, o previsibles, habida cuenta del derecho en juego, la libertad religiosa también ha sido el germen de conflictos en las relaciones de trabajo que han necesitado de la intervención del Tribunal Constitucional español. Desde luego, los trabajadores pueden ejercitar ese derecho, puesto que no sólo tiene plasmaciones en la esfera extralaboral, sino que cuenta con evidente incidencia en la relación de trabajo. Comoquiera que determinados derechos laborales en España tienen un origen religioso incuestionable, como sucede con la preferencia por el domingo como día de descanso semanal, se justifica que quienes no profesen el catolicismo soliciten una adaptación a las peculiaridades propias de sus creencias. Desde otra perspectiva, la libertad religiosa puede ser invocada incluso por el empleador, sea persona física o jurídica, cuando su actividad esté regida por un determinado ideario que pretende difundir.

En consecuencia, los litigios que han alcanzado al Tribunal Constitucional podrían clasificarse en tres grupos. En primer lugar, las relaciones laborales en las llamadas empresas de tendencia o ideológicas -en muchas ocasiones 
el ideario se asienta en creencias religiosas- suscitan una problemática específica. En segundo lugar, el peculiar procedimiento de selección de los profesores de religión en centros públicos ha obligado al Tribunal a clarificar si la no renovación de un contrato de trabajo puede estar basada en criterios ajenos al rendimiento profesional, y de ordinario vinculados a la vida personal del trabajador. $Y$ en tercer lugar, el Tribunal Constitucional también ha debido pronunciarse sobre la necesidad de que la empresa adapte su organización y sus procedimientos para ajustarse a las convicciones religiosas de un trabajador que solicita determinadas modificaciones para que su prestación de servicios no resulte incompatible con la libertad religiosa.

Se trata, por supuesto, de situaciones no idénticas, con perfiles propios. Las dos primeras responden a contextos o colectivos muy particulares, lo que exige, sin duda, una solución también peculiar, adaptada al contexto. En cambio, la tercera cuestión tiene una dimensión futura más relevante, en apariencia, y constituye un aspecto nuclear o básico para determinar con nitidez el contenido y alcance de la libertad religiosa. Curiosamente, el Tribunal Constitucional sólo se ha pronunciado en una ocasión sobre la que se ha dado en llamar vertiente positiva de la libertad religiosa. En cambio, las sentencias sobre la selección de los profesores de religión en centros públicos y sobre las empresas de tendencia ya conforman un cuerpo de doctrina bastante consolidado.

En conjunto, el Tribunal Constitucional ha diseñado el alcance y contenido de la libertad religiosa, y ha dibujado las fronteras con otros derechos, como los que le corresponden al trabajador por su condición de tal, o al empleador como titular de la organización productiva y, con ello, del poder de dirección. La coexistencia y compatibilización de todos esos derechos no resulta siempre sencilla, de modo que la jurisprudencia ha debido poner en relación los diferentes intereses y valores en juego.

\section{CONTENIDO Y LÍMITES DE LA LIBERTAD RELIGIOSA EN SU CONFIGURACIÓN LEGAL}

El reconocimiento constitucional de la libertad religiosa necesita de un desarrollo normativo que perfile adecuadamente los contornos de ese derecho. Esa labor es cumplida por la LO 7/1980, de 5 de julio. Como es lógico, esa norma proscribe la discriminación por tal circunstancia, advirtiendo que «no podrán alegarse motivos religiosos para impedir a nadie el ejercicio de cualquier trabajo o actividad o el desempeño de cargos o funciones públicas» (art. 1.2). Respecto de su contenido, el art. 2 de esa LO 7/1980, precisa que la libertad religiosa y de culto comprende el derecho de toda persona a:

- Profesar las creencias religiosas que libremente elija o no profesar ninguna; cambiar de confesión o abandonar la que tenía; manifestar libremente sus propias creencias religiosas o la ausencia de las mismas, o abstenerse de declarar sobre ellas. 
- Practicar los actos de culto y recibir asistencia religiosa de su propia confesión; conmemorar sus festividades; celebrar sus ritos matrimoniales; recibir sepultura digna, sin discriminación por motivos religiosos, y no ser obligado a practicar actos de culto o a recibir asistencia religiosa contraria a sus convicciones personales.

- Recibir e impartir enseñanza a información religiosa de toda índole, ya sea oralmente, por escrito o por cualquier otro procedimiento; elegir para sí, y para los menores no emancipados e incapacitados, bajo su dependencia, dentro y fuera del ámbito escolar, la educación religiosa y moral que esté de acuerdo con sus propias convicciones.

- Reunirse o manifestarse públicamente con fines religiosos y asociarse para desarrollar comunitariamente sus actividades religiosas de conformidad con el Ordenamiento Jurídico General y lo establecido en la presente Ley Orgánica.

Con el fin de garantizar la eficacia de estas previsiones, el art. 2.3 de la misma norma encomienda a los poderes públicos la tarea de adoptar «las medidas necesarias para facilitar la asistencia religiosa en los establecimientos públicos militares, hospitalarios, asistenciales, penitenciarios y otros bajo su dependencia, así como la formación religiosa en centros docentes públicos».

Obviamente, la libertad religiosa y de culto cuenta con restricciones, aunque el art. 3 LO 7/1980 parece configurar un «único límite», cual es «la protección del derecho de los demás al ejercicio de sus libertades públicas y derechos fundamentales, así como la salvaguardia de la seguridad, de la salud y de la moralidad pública, elementos constitutivos del orden público protegido por la Ley en el ámbito de una sociedad democrática». La interpretación de los límites de un derecho fundamental ha de ser, obviamente, restrictiva, y por ello no cabe invocar este precepto con carácter preventivo en virtud de presunciones o prejuicios (STC 46/2001, de 15 de febrero). En cualquier caso, no se contemplan en la norma mecanismos específicos para compatibilizar el ejercicio de ese derecho con las obligaciones laborales.

\section{LA MODALIZACIÓN DE LOS DERECHOS Y DEBERES LABORALES EN LAS EMPRESAS DE TENDENCIA DE CARÁCTER RELIGIOSO: LA STC 5/1981, DE 13 DE FEBRERO, COMO REFERENTE PRINCIPAL}

Como es sabido, las denominadas empresas de tendencia plantean una problemática singular, pues defienden un determinado ideario que ha de ser respetado, e incluso la libertad religiosa del trabajador puede quedar de facto suprimida en el contexto de la relación laboral cuando se encomiendan funciones características de la «tendencia» empresarial; en cambio, el desempeño de tareas «neutras» obliga a desvincular la actividad del trabajador del ideario. Desde esa perspectiva, la "libertad religiosa de la empresa", si tal expresión se admite, no puede anular completamente la vertiente negativa o pasiva -privada o íntima si se quiere- de la libertad religiosa del trabajador, 
y sólo caben limitaciones a esa libertad religiosa cuando se cause un perjuicio al empleador, ya sea al normal desarrollo de la actividad, ya sea a su imagen o a cualquier otro aspecto que proporcione una causa justificada para restringir el alcance de un derecho fundamental.

El Tribunal Constitucional tuvo ocasión de sentar esta doctrina, o al menos de establecer sus pautas básicas, en la STC 5/1981, de 13 de febrero -con argumentos reiterados posteriormente en la STC 77/1985, de 27 de junio-, que conocía de un recurso de inconstitucionalidad frente a la Ley Orgánica 5/1980, de 19 de junio, por la que se regulaba el Estatuto de Centros Escolares. Esa norma, hoy derogada, reconocía el derecho de los propietarios de los centros a establecer un ideario, que prevalecía sobre los derechos de los trabajadores, pues el ideario constituía un límite explícito a la libertad de enseñanza de los profesores.

El Tribunal Constitucional construye en esta ocasión la doctrina con cierto carácter preventivo, y quizá pedagógico, para anticipar las posibles soluciones en litigios individuales que eventualmente se pudieran tramitar por la vía del recurso de amparo. El punto de partida es el reconocimiento del derecho de los titulares de centros privados a establecer un ideario. Tal derecho, a juicio del TC, forma parte de la libertad de creación de centros (art. 27.6 CE), una peculiaridad que permite establecer diferencias respecto de la libertad de empresa (art. $38 \mathrm{CE})$.

Ese ideario, pese a que «no está constreñido a los aspectos religiosos y morales de la actividad educativa», tiene límites distintos a los que derivarían de la libertad de expresión, ya que el art. 27.6 CE exige el respeto a los «principios constitucionales». En este punto, la sentencia considera que el ideario sólo resultará conforme a la Carta Magna cuando no contraríe los principios enunciados en el Título Preliminar de la Constitución (libertad, igualdad, justicia, pluralismo, unidad de España, etc.), ni los derechos fundamentales. Además, ha de garantizarse que la enseñanza proporcione determinados valores, también constitucionales (principios democráticos de convivencia, etc.).

Es claro que ese ideario puede chocar con la libertad de enseñanza de los docentes (art. 27.1 CE), que en expresión de la sentencia «puede ser entendida como una proyección de la libertad ideológica y religiosa y del derecho a expresar y difundir libremente los pensamientos, ideas u opiniones que también garantizan y protegen otros preceptos constitucionales (especialmente arts. 16.1 y 20.1 a)» (FJ $7^{\circ}$ ). El Tribunal Constitucional se decanta por atribuir la libertad de cátedra a todos los docentes, pero advierte que ese derecho es de diferente intensidad en función, por un lado, del carácter público o privado del centro, y, por otro, del nivel de enseñanza donde la docencia se imparta.

En los centros públicos la libertad de cátedra tiene un «contenido negativo uniforme en cuanto que habilita al docente para resistir cualquier mandato de dar a su enseñanza una orientación ideológica determinada, 
es decir, cualquier orientación que implique un determinado enfoque de la realidad natural, histórica o social dentro de los que el amplio marco de los principios constitucionales hacen posible. Libertad de cátedra es, en este sentido, noción incompatible con la existencia de una ciencia o una doctrina oficiales». En consecuencia, el TC propugna la «neutralidad ideológica de la enseñanza en los centros escolares públicos», de modo que los docentes deben «renunciar a cualquier forma de adoctrinamiento ideológico, que es la única actitud compatible con el respeto a la libertad de las familias que, por decisión libre o forzadas por las circunstancias, no han elegido para sus hijos centros docentes con una orientación ideológica determinada y explícita» $\left(\mathrm{FJ} 9^{\circ}\right.$. En el plano del contenido positivo, las facultades del docente en la determinación de la materia a transmitir son mayores en los niveles educativos superiores que en los inferiores, donde el intervencionismo público en la determinación de los planes de estudios y de las herramientas pedagógicas es mucho mayor.

En cambio, los centros privados tienen la posibilidad de ajustar su actividad a un ideario, aunque colisione con la libertad de cátedra de los profesores. Como punto de partida, la sentencia afirma que el conocimiento de ese ideario no obliga al profesor «ni a convertirse en apologista del mismo, ni a transformar su enseñanza en propaganda o adoctrinamiento, ni a subordinar a ese ideario las exigencias que el rigor científico impone a su labor». Sin embargo, su posición y su función en el contexto del centro le obliga a respetar ese ideario, y a no «dirigir ataques abiertos o solapados» contra el mismo $\left(\mathrm{FJ} 10^{\circ}\right)$. La sentencia, asimismo, advierte que la conducta extralaboral del docente podría ser considerada, en determinados supuestos, como un ataque a ese ideario ( $\left.F J 1^{\circ}\right)$.

En esta sentencia inicial el Tribunal Constitucional no se pronunciaba sobre ningún supuesto de hecho en concreto, sino que procedía a formular una doctrina genérica, como es propio de un recurso de inconstitucionalidad. La oportunidad de aplicar estas reglas no se presentó hasta la STC 47/1985, de 27 de marzo, en un recurso de amparo interpuesto por una profesora de un colegio religioso que había sido despedida por discrepar del ideario del centro. El TC, partiendo de la precedente STC 5/1981, de 13 de febrero, insiste en que los trabajadores han de respetar el ideario de la empresa, y no pueden «dirigir ataques abiertos o solapados contra este ideario». En consecuencia, «una actividad docente hostil o contraria al ideario de un Centro docente privado puede ser causa legítima de despido del profesor al que se le impute tal conducta o tal hecho singular, con tal de que los hechos o el hecho constitutivos de "ataque abierto o solapado" al ideario del Centro resulten probados por quien los alega como causa de despido, esto es, por el empresario», si bien «la simple disconformidad de un Profesor respecto al ideario del Centro no puede ser causa de despido, si no se ha exteriorizado o puesto de manifiesto en alguna de las actividades educativas del Centro» $\left(\mathrm{FJ} \mathrm{3}^{\circ}\right)$. 
La sentencia afirma que el despido por motivos de carácter ideológico no se justifica por la mera disconformidad del trabajador con el ideario del centro, sino que resulta imprescindible que haya fricciones «consistentes en actos concretos de la Profesora y en una actividad contraria (o al menos no ajustada) al ideario» (FJ $4^{\circ}$ ). La mera disconformidad no exteriorizada no justifica el despido. Esa es la razón, precisamente, de que el tribunal concluya declarando nulo por discriminatorio el despido de la profesora, en la medida en que el empleador no probó ese ataque al ideario.

Esa doctrina sería objeto de cierta matización en la STC 106/1996, de 12 de junio. El despido no afectaba a un profesor de un colegio religioso, sino a una auxiliar de clínica de un hospital, cuya titularidad correspondía a una orden religiosa. Sucintamente, el despido se produjo tras mostrar la trabajadora su malestar con el capellán cuando este decidió, a la vista de que los enfermos no acudían a la capilla del hospital, subir a las plantas para darles la comunión, lo que hizo, según palabras de la sentencia, «portando el cáliz y entonando cánticos religiosos». La trabajadora, al ver tal situación, delante de los enfermos $-y$ del capellán- hizo manifestaciones del siguiente tenor: «No sé como no les da vergüenza», «esto parece un picnic», «estos son los humanitarios» y «si mi madre estuviese aquí los denunciaría».

De partida, la sentencia reconoce que la posibilidad de establecer un ideario no se limita a los centros docentes religiosos, y que por tanto otro tipo de entidades gozan de la misma facultad $\left(\mathrm{FJ} 3^{\circ}\right)$. Y en segundo lugar, advierte que la doctrina precedente se había diseñado tomando como referente la docencia, y que por tanto no puede extrapolarse a cualquier otra actividad, y en particular a tareas de carácter técnico, neutras desde una perspectiva ideológica, como sucedía con la recurrente en amparo, auxiliar de clínica $\left(F J 4^{\circ}\right)$. En este caso no se produce una confrontación entre la libertad de cátedra y la libertad de enseñanza, sino entre la libertad de expresión y el poder de dirección del empleador. El eventual carácter ideológico de la entidad no introduce ninguna especialidad.

Por supuesto, también resulta determinante que la función del hospital, aun dependiente de una orden religiosa, consiste en prestar asistencia sanitaria, y no en difundir el mensaje religioso. Por consiguiente, se considera desproporcionada la decisión de despedir a una auxiliar de clínica que había mostrado su disconformidad con la decisión del capellán de dar comunión a los enfermos en sus propias habitaciones. EI TC entiende que las expresiones de la trabajadora no constituían justa causa de despido en ese contexto, pues «constituyen ciertamente reproches sin duda molestos o hirientes e incluso despectivos, pero no gravemente vejatorios» ( $\left.\mathrm{FJ} 7^{\circ}\right)$.

En último término, el Tribunal Constitucional también ha debido dilucidar si el empleador puede exigir al trabajador su participación en actos de religiosos o de culto. Curiosamente, los litigios no se han suscitado en el seno de entidades ideológicas, sino en el ámbito público. Dos son los casos de referencia. En primer lugar, la STC 177/1996, de 11 de noviembre, que se 
pronuncia sobre la negativa de un militar a rendir honores a la Virgen en un acto militar, incumpliendo la orden de sus superiores. En segundo lugar, la STC 101/2004, de 2 de junio, que resolvía el recurso de amparo de un policía nacional al que se había encomendado participar en la procesión de una hermandad, que en sus Estatutos había nombrado como Hermano Mayor al Cuerpo Nacional de Policía. En ambos casos, el TC afirma que la libertad religiosa, en su vertiente negativa, permite al individuo negarse a participar en estos actos de culto que son contrarios a sus creencias, máxime cuando el empleador es una Administración Pública, vinculada por los principios de neutralidad ideológica y aconfesionalidad del Estado. Seguramente esa vertiente negativa de la libertad religiosa ampararía asimismo al trabajador en una empresa ideológica, pero el TC no lo ha manifestado con claridad hasta el momento.

4. VALORES Y PRINCIPIOS QUE SUBYACEN EN LA JURISPRUDENCIA CONSTITUCIONAL SOBRE LAS EMPRESAS DE TENDENCIA

Pese a que a menudo resulta complejo deducir los valores y principios sobre los que se apoya la jurisprudencia constitucional, ya que no siempre son explícitos, la doctrina sentada en relación con las empresas ideológicas aporta datos suficientes para identificar tales valores y principios, mediante los que se pretende conciliar los distintos intereses que están en juego. Si hubiera que identificar los dos valores o criterios con mayor peso en la decisión, seguramente habría que decantarse, de un lado, por la aconfesionalidad del Estado, y, de otro, por la pretensión de garantizar el pluralismo religioso, y, en último término, ideológico. Por supuesto, no se trata de valores o principios contrapuestos, sino netamente interrelacionados, pues la aconfesionalidad del Estado conlleva, en un Estado social y democrático de Derecho, basado en la libertad, el respeto al pluralismo ideológico.

Esas dos premisas permiten al Tribunal rechazar el ideario en la enseñanza pública -aconfesionalidad- y admitirlo sin ambages en la privada -pluralismo-, con objeto de ofrecer los ciudadanos -principalmente a los padres en su decisión sobre la educación de los hijos (art. 27.3 CE)- todas las opciones posibles, y así facilitar el «pleno desarrollo de la personalidad humana en el respeto a los principios democráticos de convivencia y a los derechos y libertades fundamentales» (art. 27.2 CE). La neutralidad ideológica en el ámbito público se contrapone con la completa libertad ideológica en el ámbito privado, libertad que no puede ser restringida por los poderes públicos.

Se deduce de esta toma de posición, por consiguiente, un principio de intervención mínima estatal sobre la educación privada. El Estado debe respetar las distintas opciones e iniciativas educativas que surjan en el ámbito privado, siempre, desde luego, que no lesionen derechos o libertades fundamentales de los individuos, o no contraríen el orden público. Son, por consiguiente, límites muy estrictos.

Para garantizar la inmunidad frente a injerencias estatales el Tribunal Constitucional no acude a la libertad de empresa (art. $38 \mathrm{CE}$ ) de los centros 
docentes privados, seguramente porque su ubicación constitucional no es todo lo garantista que esa doctrina requiere. En cambio, se apoya en el art. $27 \mathrm{CE}$, y en concreto en la libertad de creación de centros docentes que se reconoce como contenido de la libertad de enseñanza (art. 27.6 CE). Esa libertad de creación de centros docentes incluye, a juicio del TC, la posibilidad de establecer un ideario, y también la libertad de no hacerlo.

Este matiz es, probablemente, determinante, porque el Tribunal reconoce que la libertad de empresa no habilita al empleador para imponer un ideario. En otras palabras, no todo empleador es, o puede ser, ideológico, porque no es una cuestión estrictamente de voluntad unilateral. El Tribunal deja entrever que debe existir un soporte constitucional más intenso para justificar ese carácter ideológico, y de perfiles distintos a la libertad de empresa, un soporte más conectado, por tanto, con la faceta ideológica. El derecho fundamental de libertad sindical (art. 28.1 CE), por un lado, y la libertad de asociación (art. 22 CE), por otro, podrían ser válidos puntos de apoyo, y justificarían el carácter de empresas de tendencia de los sindicatos y de los partidos políticos, por ejemplo.

Ahora bien, en otro caso no parece justificarse la limitación de los derechos de los trabajadores por el sesgo ideológico. La STC 106/1996 resulta suficientemente clarificadora, al rechazar la aplicación de esa doctrina sobre empresas de tendencia a un hospital regido por una Orden religiosa, invocando la «función social que cumple el centro donde se presta el trabajo, que en este caso es la hospitalaria». Los rasgos característicos de la actividad del empleador, por tanto, condicionan la posibilidad de introducir un ideario.

5. LA PROBLEMÁTICA ESPECÍFICA DE LOS PROFESORES DE RELIGIÓN EN CENTROS PÚBLICOS (STC 38/2007, DE 15 DE FEBRERO)

La neutralidad ideológica de la enseñanza pública y el legítimo derecho de las confesiones religiosas a transmitir sus creencias colisionan en el específico régimen jurídico de contratación de los profesores de religión en centros públicos. Esos profesores de religión, como dispone el art. 3 del Acuerdo entre el Estado español y la Santa Sede sobre Enseñanza y Asuntos Culturales, firmado en la Ciudad del Vaticano el 3 de enero de 1979 (Instrumento de ratificación publicado en el BOE de 15 de diciembre de ese mismo año), son designados, para cada año escolar, «por la autoridad académica entre aquellas que el ordinario diocesano proponga para ejercer esta enseñanza». La DA $3^{a}$ LO 2/2006, de 3 de mayo, de Educación, dispone que «la propuesta para la docencia corresponderá a las entidades religiosas y se renovará automáticamente cada año», y precisa que «la remoción, en su caso, se ajustará a derecho».

Al margen de tales previsiones, esa facultad de propuesta no se sujeta a ningún límite específico, lo que, obviamente, puede generar dificultades en función de los motivos por los que la autoridad religiosa decida excluir de la propuesta a quien venía realizando esas funciones en cursos anteriores. No ha sido inhabitual, concretamente, que en el ejercicio de esa competencia 
se haya excluido de la propuesta a una persona por circunstancias relacionadas con su vida personal, sin cuestionar su aptitud profesional y el correcto cumplimiento de sus obligaciones docentes en el pasado.

El Tribunal Constitucional se ha pronunciado en numerosas ocasiones sobre esta problemática durante los últimos años. La sentencia de referencia es la STC 38/2007, de 15 de febrero, cuya doctrina fue ratificada por varias sentencias posteriores (SSTC 80 a 90/2007, de 19 de abril, y Auto 190/2009, de 23 de junio, resoluciones todas ellas que resolvían cuestiones de inconstitucionalidad). El TC aclara, y seguramente haya de ser considerado el punto de partida, que el conflicto no tiene las mismas características que el generado en las empresas de tendencia. El carácter público del empleador de los profesores de religión es una diferencia evidente, como también lo es el hecho de que la modulación de la relación laboral en las empresas de tendencia, y la obligación de no atacar el ideario, se extiende a todos los docentes, cualquiera que sea la materia que impartan, mientras que el compromiso de un profesor de religión en un centro público es muy distinto, porque, en primer lugar, el centro no tiene ideario, y, en segundo, el profesor debe transmitir una serie de contenidos y valores que se ajusten al credo de la confesión religiosa (FJ $10^{\circ}$ STC 38/2007, de 15 de febrero). Por consiguiente, los condicionamientos religiosos sobre la docencia son, en apariencia, mucho más intensos.

EI TC reconoce que la inserción de la religión católica en el sistema educativo exige la atribución de una serie de facultades y prerrogativas a la Iglesia Católica, pues otorgar al Estado un papel más activo y decisor resultaría contrario al principio de aconfesionalidad. El Estado, por tanto, ha de mantener una «actitud positiva, de naturaleza asistencial o prestacional» (FJ $5^{\circ}$ STC 38/2007).

Entre las prerrogativas que se atribuyen a la Iglesia Católica no se encuentra únicamente la facultad de determinar los contenidos de la asignatura de religión, sino también la de intervenir en la selección del profesorado a través de un juicio de idoneidad, que no se limita a constatar las aptitudes pedagógicas, sino que puede exceder del contexto académico, siempre que el «testimonio personal constituya para la comunidad religiosa un componente definitorio de su credo, hasta el punto de ser determinante de la aptitud o cualificación para la docencia, entendida en último término, sobre todo, como vía e instrumento para la transmisión de determinados valores» (FJ 50 STC 38/2007).

El juicio de idoneidad es controlable jurisdiccionalmente, y tiene como límite el orden público, pero el propio Tribunal admite que podrían valorarse aspectos relacionados con la vida privada del trabajador. La ponderación de los diversos derechos en juego es imprescindible, aunque los criterios que deben utilizarse para ello no se especifican. En estos términos, «la declaración de idoneidad no constituye sino uno de los requisitos de capacidad necesarios para poder ser contratado a tal efecto, siendo su exigencia conforme al derecho 
a la igualdad de trato y no discriminación (art. $14 \mathrm{CE}$ ) y a los principios que rigen el acceso al empleo público (art. 103.3 CE)» (FJ go STC 38/2007). En esa misma línea, el Tribunal advierte que conferir a las Administraciones Públicas la facultad de designar unilateralmente a los profesores de religión en contra de la voluntad de la confesión religiosa sería contrario a la libertad religiosa.

Una vez justificado el juicio de idoneidad, la no renovación del contrato, o, en mejor expresión, el hecho de que la confesión religiosa no incluya en su propuesta para el nuevo curso a quien venía desarrollando tales funciones, se justifica sin dificultad, como precisa la STC 128/2007, de 4 de junio, resolviendo un recurso de amparo interpuesto por un sacerdote secularizado que había contraído matrimonio civil, era padre de cinco hijos y miembro del movimiento de clérigos casados pro celibato opcional, información que él mismo proporcionó a la prensa escrita, donde había aparecido. La sentencia se apoya en la coherencia misma del mecanismo, puesto que si quien ejercía esas funciones docentes en los cursos anteriores había sido designado gracias a la propuesta eclesiástica previo juicio de idoneidad -con base exclusivamente en criterios religiosos-, no es razonable rechazar que ulteriormente, a partir de los mismos parámetros que se utilizaron en un primer momento, la confesión religiosa pueda considerar que ya no concurre la idoneidad, o que otros candidatos reúnen mayores aptitudes (FJ $4^{\circ}$ STC 128/2007).

Esta última aproximación es objeto de implícita revisión por la STC 51/2011, de 14 de abril, relativa a una profesora de religión que fue excluida de propuesta por haber contraído matrimonio civil con una persona divorciada. EI TC se apoya en su sentencia 38/2007, y advierte, en primer lugar, que el motivo alegado es de naturaleza exclusivamente religiosa -no se cuestionaba su aptitud profesional-, y, en segundo lugar, que es imprescindible ponderar adecuadamente todos los derechos en juego. Es, en este punto, donde se aprecia una mayor distancia respecto de la STC 128/2007 (que, significativamente, no se menciona); la STC 51/2011 entiende que el derecho a la libertad ideológica, en conexión con el art. $32 \mathrm{CE}$, garantiza el derecho a contraer matrimonio con la persona que se desee, y que el debido respeto a la intimidad, a la vida privada y a la dignidad no pueden situar a un trabajador ante la disyuntiva de elegir entre su vida personal y el mantenimiento de su empleo. El Tribunal insiste en que la trabajadora no había cuestionado ni atacado el credo religioso, ni había hecho «exhibición pública de su condición de casada con una persona divorciada» (FJ $12^{\circ}$ STC 51/2011), diferencias evidentes con el supuesto de hecho al que se hubo de enfrentar la STC 128/2007, y que quizá fueron determinantes del fallo. Bajo tales premisas, se concede el amparo solicitado. En la medida en que la demandante -y su esposo- han aparecido en los medios de comunicación exponiendo el $\mathrm{caso}^{2}$, se plantea la duda de si ante una eventual readmisión sería posible la futura exclusión de la propuesta basada, precisamente, en la

\footnotetext{
${ }^{2}$ Vid. http://www.elmundo.es/elmundo/2011/04/19/andalucia/1303234447.html.
} 
ahora ya pública y notoria incompatibilidad entre su situación personal y familiar y el concepto de familia defendido por la Iglesia Católica.

\section{VALORES Y PRINCIPIOS QUE SUBYACEN EN LA JURISPRUDENCIA CONSTITUCIONAL SOBRE SELECCIÓN DEL PROFESORADO DE RELIGIÓN EN CENTROS PÚBLICOS}

El Tribunal Constitucional se apoya en argumentos parcialmente coincidentes con los ya esgrimidos en las sentencias sobre las empresas de tendencia, pero también introduce criterios novedosos, por la singularidad de una problemática que no es equiparable totalmente. Entre los argumentos, valores o principios coincidentes se encuentran los de neutralidad ideológica de la enseñanza pública y aconfesionalidad del Estado. La incorporación de la religión como materia en la educación pública debe resultar compatible con esos principios, así como también la selección del profesorado. La exigencia constitucional -art. 16.3- de mantenimiento de relaciones de cooperación con las confesiones religiosas, y el Acuerdo con la Santa Sede un auténtico convenio internacional-, permiten, en primera instancia, explicar la conformidad con la Constitución de impartir la enseñanza de religión en los centros públicos.

En cualquier caso, el punto de apoyo más relevante es la libertad religiosa, en su vertiente colectiva. Esa libertad religiosa, en combinación con la aconfesionalidad del Estado, justifica que la Iglesia Católica desempeñe un papel preponderante en la delimitación de los contenidos de la asignatura de religión y en la selección del profesorado, porque si tales cometidos se atribuyeran a la Administración se estaría produciendo una injerencia contraria al carácter aconfesional del Estado. La libertad religiosa en esa vertiente colectiva se impone a la libertad religiosa individual del profesor de religión, porque seguramente es la mejor manera de garantizar un adecuado desarrollo de la libertad religiosa.

La diferencia, así pues, entre la docencia en centros privados con ideario y la docencia de la religión en centros públicos resulta evidente. Los profesores de centros privados imparten materias muy distintas, en su mayor parte neutras o asépticas -en apariencia-, como matemáticas, lengua, física, idiomas, etc. El contenido de tales materias viene parcialmente predeterminado por normas que emanan de los poderes públicos, con el propósito de garantizar el respeto a unos contenidos mínimos.

En cambio, esas normas no establecen los contenidos mínimos de la enseñanza de la religión, ni pueden hacerlo, ya que el principio de aconfesionalidad del Estado lo impide. Es la propia confesión religiosa la que fija tales contenidos, y el docente no sólo debe transmitir información, sino también una serie de valores. El adoctrinamiento es inherente a la enseñanza de la religión, puesto que la confesión religiosa pretende difundir su credo. El Tribunal Constitucional insiste en esa diferencia para justificar las prerrogativas que se conceden a la Iglesia Católica, y en su caso a otras 
confesiones religiosas, en la configuración de la enseñanza de la religión en centros públicos, incluida la selección de docentes.

En ese contexto, la jurisprudencia constitucional, pese a que garantiza el control jurisdiccional de la decisión, que tiene que respetar los principios y valores constitucionales, parece reconocer que la propuesta efectuada por la instancia religiosa competente será legítima en tanto se funde en criterios estrictamente religiosos. Esos criterios pueden entroncar, como señala la STC 128/2007, FJ $6^{\circ}$, con la notoriedad o publicidad de una determinada conducta contraria a los valores religiosos. El voto particular a esta sentencia introduce consideraciones interesantes, y aboga por incorporar en el juicio de constitucionalidad el criterio de los actos propios. A la postre, la confesión religiosa conocía cuál era la situación personal del interesado, y sus creencias, en el momento de la propuesta inicial, y de las sucesivas propuestas de «renovación». En la medida en que se había concedido la idoneidad concurriendo las mismas circunstancias personales y familiares, no había, a juicio del voto particular, ninguna razón sobrevenida que justificase la declaración de inidoneidad. El voto particular, por consiguiente, trata de evitar la anulación de facto de los derechos del trabajador.

Sin embargo, la doctrina mayoritaria aboga por la prevalencia casi absoluta de la dimensión colectiva de la libertad religiosa, afirmando que «la especial idoneidad para la enseñanza de la religión católica no es una condición subjetiva, derivada de la hipotética aplicación de una norma jurídica estatal, cuyo no reconocimiento por la autoridad eclesiástica pueda, en su caso, vulnerar tal norma, sino que es una condición que se inserta en un ámbito puramente religioso, y depende de una valoración del mismo signo. Se parte de una opción personal que, como cualquier otra, lógicamente implica una autolimitación respecto de opciones diferentes, opción previa que a la hora del posible ejercicio de otros derechos fundamentales puede justificar la modulación de las consecuencias de éstos para no desvirtuar o desnaturalizar dicha opción inicial» (FJ $4^{\circ}$ STC 128/2007).

Seguramente, detrás de esta toma de posición late la pretensión del Tribunal Constitucional de garantizar absolutamente la neutralidad del Estado, y de todas sus instituciones, ante el fenómeno religioso. El control jurisdiccional de las propuestas eclesiásticas, que el Tribunal considera garantía para la salvaguardia de los derechos fundamentales de los profesores de religión en centros públicos, queda prácticamente vacío de contenido al admitir que si la falta de propuesta de quien venía desempeñando las funciones docentes se funda en motivos religiosos, la decisión no merece reproche constitucional, salvo, quizás, en circunstancias muy excepcionales que no se adivinan con claridad de la lectura de las sentencias.

El pleno desarrollo de la libertad religiosa en esa dimensión colectiva no resulta fácil de encajar con otra serie de principios, valores o criterios, incluyendo no sólo la libertad religiosa individual o la libertad de expresión en último término, quien pertenece a una entidad o asociación de carácter 
ideológico es consciente de que debe acomodar ciertas pautas de conducta al ideario-, sino incluso los principios de igualdad, mérito y capacidad que deben presidir el acceso al empleo público.

Es probable que el Tribunal Constitucional estimase que la única manera de garantizar la autonomía de las confesiones religiosas y la aconfesionalidad del Estado en una cuestión tan fronteriza, y tan marcadamente ideológica además, como la enseñanza de la religión en centros públicos, pasaba por reconocer espacios de actuación prácticamente independientes, competencias o atribuciones, en definitiva, no susceptibles de injerencia, al menos por parte de las Administraciones Públicas.

En fin, el resto de valores, principios o criterios que maneja el Tribunal Constitucional o bien actúan en un segundo plano, a modo de complemento, o bien son derivaciones de los ya señalados. Uno de esos criterios adicionales en los que el Tribunal muestra cierta insistencia -porque otros, como el derecho de los padres a elegir la educación religiosa de los hijos, meramente se enuncia (FJ $12^{\circ}$ STC 38/2007)- es el que propugna el respeto a las decisiones del legislador, y al legítimo margen de actuación que le corresponde. EI TC aclara que las opciones para configurar una determinada institución pueden ser múltiples, y que la concreta elección del legislador puede ser valorada desde perspectivas muy diversas, incluso a partir de la propia idea de justicia. Ahora bien, ninguna de esas perspectivas permite automáticamente considerar que el legislador ha incurrido en la arbitrariedad prohibida por el art. 9.3 CE (FJ 11 STC 38/2007).

7. LA DOBLE FACETA ACTIVA Y PASIVA DE LA LIBERTAD RELIGIOSA

Desde una perspectiva tradicional, el reconocimiento de la libertad religiosa se ha limitado a su vertiente exclusivamente negativa o pasiva, es decir, al derecho del trabajador a no declarar sobre sus creencias, a la prohibición del empresario de indagar sobre ellas, al derecho del trabajador a no ser discriminado por sus convicciones, etc. Se exige del empresario, en definitiva, una conducta neutral o no confesional. Es, sin duda, la dimensión que hasta ahora prevalece en la jurisdicción, y que conviene intensificar, porque la discriminación por razones religiosas está aumentando en los últimos años, según ha puesto de manifiesto la OIT en su informe sobre La igualdad en el trabajo: afrontar los retos que se plantean, Ginebra, 2007, pág. 37 (dicho informe puede consultarse en la siguiente dirección: http://www.ilo.org/wcmsp5/groups/public/---dgreports/---dcomm/---webdev/ documents/publication/wcms_082609.pdf).

Sin embargo, la libertad religiosa cuenta con una vertiente positiva o activa, que, en el marco de la relación laboral, permitiría exigir al empresario determinadas adaptaciones o modulaciones que asegurasen el pleno respeto a la libertad religiosa de sus trabajadores. No es, en absoluto, un problema nuevo, pero posiblemente exigirá un replanteamiento en el futuro, porque la inmigración traerá consigo mayor heterogeneidad de confesiones 
religiosas, que suscitarán problemas todavía infrecuentes en España, pero a los que ya han tenido que hacer frente en otros países con mayor diversidad cultural, étnica y religiosa, especialmente Estados Unidos.

El ordenamiento español no contempla reglas específicas más allá del reconocimiento de los principios de igualdad y no discriminación. Los Acuerdos con las distintas confesiones religiosas celebrados en 1992, quizá los instrumentos más adecuados para propiciar un reconocimiento efectivo de la libertad religiosa en su vertiente activa o positiva, no cumplen ese propósito.

En este sentido, la Ley 24/1992, de 10 de noviembre, recogió el Acuerdo de Cooperación entre el Estado español y la Federación de Entidades Religiosas Evangélicas de España (FEREDE), y en su art. 12 dispone que «el descanso laboral semanal, para los fieles de la Unión de Iglesias Adventistas del Séptimo Día y de otras Iglesias evangélicas, pertenecientes a la Federación de Entidades Religiosas Evangélicas de España, cuyo día de precepto sea el sábado, podrá comprender, siempre que medie acuerdo entre las partes, la tarde del viernes y el día completo del sábado, en sustitución del que establece el artículo 37.1 del Estatuto de los Trabajadores como regla general»».

La Ley 25/1992, de 10 de noviembre, mediante la que se aprueba el Acuerdo de Cooperación con la Federación de Comunidades Israelitas de España, hace lo propio en su art. 12.1. El art. 12.2 de ese Acuerdo permite cambiar determinadas fiestas reconocidas en el art. 37.2 ET por festividades «que según la Ley y la tradición judías, tienen el carácter de religiosas», con carácter retribuido y no recuperable. Esa modificación, no obstante, debe producirse «a petición de las personas a que se refiere el número anterior, y en los términos previstos en el mismo», remisión al art. 12.1 del Acuerdo que implica un pacto entre empresario y trabajador para poder hacer efectivo el derecho al cambio de disfrute de la fiesta.

Por su parte, la Ley 26/1992, de 10 de noviembre, por la que se aprueba el Acuerdo de Cooperación del Estado con la Comisión Islámica de España, recoge en su art. 12.1 el derecho de los miembros de las Comunidades Islámicas a «solicitar la interrupción de su trabajo los viernes de cada semana, día de rezo colectivo obligatorio y solemne de los musulmanes, desde las trece treinta hasta las dieciséis treinta horas, así como la conclusión de la jornada laboral una hora antes de la puesta del sol, durante el mes de ayuno (Ramadán)», si bien será «necesario el previo acuerdo entre las partes» y «las horas dejadas de trabajar deberán ser recuperadas sin compensación alguna». También cabe pactar la sustitución de las fiestas del art. 37.2 ET por las propias de la religión islámica, a tenor del art. 12.2 del Acuerdo.

Prescindiendo de las cuestiones relativas a la asistencia sanitaria por no estar directamente relacionadas con la relación de trabajo (SSTC 166/1996, de 28 de octubre, y 154/2002, de 18 de julio), los conflictos surgirán sin duda 
hacia el futuro en el terreno laboral, y el ámbito potencial de esos litigios es muy amplio, e incluso puede alcanzar a la prevención de riesgos laborales. Parece claro que el trabajador no puede negarse por motivos religiosos a utilizar determinada ropa de trabajo, ni tampoco a someterse a reconocimientos médicos obligatorios si no es razonablemente posible que se utilice un método inocuo para sus convicciones; se impone en cualquier caso una valoración casuística y la apreciación de proporcionalidad será indispensable con el propósito de lograr una solución conciliadora que tome en cuenta adecuadamente todos los intereses concurrentes. No en vano, soluciones de esa índole vienen proporcionando los tribunales estadounidenses desde hace ya varias décadas (la doctrina general puede consultarse en http://www.eeoc.gov/laws/types/religion.cfm), al exigir al empresario una reasonable accomodation en las condiciones de trabajo para no impedir el ejercicio de la libertad religiosa, salvo que esa modificación razonable sea especialmente costosa o compleja (undue hardship on the employers' legitimate business interests). En verdad, esa acomodación razonable de la organización del trabajo debería ser exigible no sólo respecto de la libertad religiosa, sino también en relación con el ejercicio de cualesquiera otros derechos fundamentales; a la postre, la buena fe debe presidir el comportamiento de las dos partes ligadas por el contrato de trabajo.

\section{LA VERTIENTE ACTIVA O POSITIVA DE LA LIBERTAD RELIGIOSA EN LA JURISPRUDENCIA CONSTITUCIONAL (STC 19/1985, DE 13 DE FEBRERO)}

En teoría, dentro de la vertiente activa o positiva de la libertad religiosa pueden a su vez distinguirse dos estratos, pues la afectación a la organización empresarial por causa de las convicciones religiosas de los trabajadores no siempre tiene la misma intensidad. El primero de esos niveles se limitaría a reconocer al trabajador la posibilidad de exteriorizar sus creencias, y a requerir del empresario el correlativo deber de respeto pese a que pudieran generarse situaciones inusuales. Se trataría, a la postre, de extender el principio de neutralidad e indiferencia hacia la religión del trabajador a cierto tipo de comportamientos efectuados en tiempo y lugar de trabajo que para la empresa sean inocuos, o que no causen un trastorno de consideración ( $v$.gr., exhibir un crucifijo). En un segundo nivel, la vertiente activa o positiva de la libertad religiosa podría hacer surgir el derecho a exigir del empresario adaptaciones organizativas para garantizar el respeto a las convicciones del trabajador.

No es, esta última, una problemática completamente desconocida en España, y ya hace más de dos décadas que el TC tuvo ocasión de pronunciarse sobre las ausencias al trabajo durante determinados días que la religión del trabajador prescribía como de descanso obligatorio. En concreto, la STC 19/1985, de 13 de febrero, se ocupó de un despido disciplinario decidido por la empresa a causa de las faltas al trabajo de una empleada miembro de la Iglesia Adventista del Séptimo Día, que se negaba a trabajar desde la puesta del sol del viernes a la del sábado por ser 
contrario a sus creencias. La trabajadora había solicitado el cambio de turno o, al menos, que su ausencia únicamente comportase pérdida de salario con eventual compensación en otras horas, solicitud rechazada por la empresa, que, ante las faltas reiteradas al trabajo, procedió al despido.

La sentencia desestima la pretensión de la trabajadora, sobre la base de que la seguridad jurídica se vería lesionada si el cumplimiento de los contratos dependiera de que su contenido no contrariase la religión que en cada momento profesen trabajador o empresario. En suma, uno de los contratantes no puede forzar al otro, sobre la base de la libertad religiosa, a alterar lo pactado en contrato si esas cláusulas o estipulaciones no vulneran el ordenamiento jurídico. El TC recuerda que no se había lesionado la vertiente negativa de la libertad religiosa, porque en ningún caso se pretendía obligar a la trabajadora a declarar sobre sus creencias, sino que simplemente la empresa había rechazado modificar el tiempo de trabajo de la demandante para hacer compatible el trabajo con su fe. En este contexto, el respeto a la libertad religiosa de la trabajadora facultaría al empresario para alterar el horario con una causa que justificaría una medida individual y excepcional, pero en ningún caso está obligado a ello legal o constitucionalmente.

EI TC también advierte que el origen cristiano de la preferencia por el domingo como día de descanso semanal no es suficiente para declarar la lesión del derecho fundamental del art. $16 \mathrm{CE}$, puesto que el descanso dominical ha superado ese origen confesional y se ha convertido en tradición, perdiendo esa neta vinculación religiosa para incorporarse al acervo cultural, máxime tras el reconocimiento del carácter aconfesional del Estado (art. 16.3 CE). A la postre, el día de descanso puede ser modificado por acuerdo de las partes, pues su fijación en domingo constituye únicamente la «regla general» y no un imperativo jurídico (art. 37.1 ET).

\section{VALORES Y PRINCIPIOS QUE SUBYACEN EN LA JURISPRUDENCIA CONSTITUCIONAL SOBRE LA VERTIENTE ACTIVA DE LA LIBERTAD RELIGIOSA}

Como en su momento se advirtió, los principios de neutralidad ideológica y aconfesionalidad del Estado, combinados con el firme propósito del TC de permitir el desarrollo y ejercicio efectivo de la libertad religiosa, especialmente en su vertiente colectiva, sirvieron de base a la doctrina sobre las relaciones laborales en las empresas de tendencia y la peculiar situación de los profesores de religión en centros públicos. Se garantizaba con ello el pluralismo religioso, así como el derecho de los padres a elegir la educación de los hijos.

La vertiente activa o positiva de la libertad religiosa exige un cambio de enfoque, por motivos diversos. En primer lugar, ya no está en juego la dimensión colectiva de la libertad religiosa, sino estrictamente la individual: es el trabajador quien solicita una adaptación de las condiciones de trabajo para poder cumplir sus obligaciones religiosas. Y en segundo lugar, no están en cuestión ni la aconfesionalidad del Estado ni la neutralidad ideológica de 
las Administraciones Públicas, máxime cuando el empleador es, a menudo, un sujeto privado. En otras palabras, no se producen injerencias externas que vulneren de forma directa el derecho del trabajador a su libertad religiosa, porque no se le exige que declare sobre sus creencias, ni se le impide exteriorizarlas, ni se le impone participar en actividades de culto de confesiones ajenas. No hay, así pues, un ataque explícito contra las creencias del trabajador, sino que es él mismo quien toma la iniciativa para solicitar modificaciones que le permitan compatibilizar su fe con las obligaciones laborales.

En cierto modo, es una problemática con ciertos paralelismos con la que deriva de las cargas familiares, porque es evidente que los empleadores no toman decisiones organizativas con el fin de impedir que los trabajadores atiendan sus obligaciones o compromisos familiares. Las medidas de conciliación de la vida laboral y familiar procuran conseguir un equilibrio entre los legítimos intereses del empresario y los también legítimos intereses de una persona que, a su vez, trabaja por cuenta ajena. Desde esa perspectiva, el legislador ha considerado atendibles ciertas circunstancias familiares 0 personales, y ha permitido que en tales situaciones se modulen las obligaciones y deberes laborales. Además de las reglas específicas de conciliación, los derechos reconocidos a las víctimas de violencia de género son también ejemplos evidentes.

Sin embargo, esas reglas de conciliación o compatibilización no alcanzan explícitamente a circunstancias distintas, como sucede, en este caso, con las creencias religiosas. El legislador se ha limitado a reconocer derechos en situaciones de índole familiar, fundamentalmente, y no a partir de circunstancias marcadamente personales, e incluso íntimas, como la ideología o las creencias, más allá de lo que pueda derivarse de la cláusula de conciencia de los profesionales de la información (LO 2/1997, de 19 de junio), y, quizá, aunque es muy dudoso, de la objeción de conciencia.

En ese contexto, las posibles modulaciones o adaptaciones de las condiciones de trabajo para hacerlas compatibles con las creencias religiosas deben deducirse, en su caso, directamente de la Constitución, o bien de la Ley Orgánica que desarrolle el correspondiente derecho fundamental. En relación con la libertad religiosa, ni el art. 16 CE, ni la Ley Orgánica de Libertad Religiosa contemplan una posible colisión con el trabajo, porque conciben la libertad religiosa del individuo desde una perspectiva íntima, o intimista, y su proyección pública como una mera manifestación de creencias o ideas que no deberían colisionar con las obligaciones dimanantes de un contrato, en este caso de trabajo. Las eventuales injerencias empresariales se entienden salvadas por el juego conjunto de los arts. 14 y $16 \mathrm{CE}$.

Sin embargo, algunos derechos laborales, principalmente el descanso semanal y ciertas fiestas, tienen un origen marcadamente vinculado a la religión católica, por lo que no resulta extraño que se puedan generar conflictos con trabajadores de religiones distintas, como sucede en el asunto resuelto por la STC 19/1985. El Tribunal maneja criterios y valores distintos, 
algunos explícitos, otros implícitos, y en ocasiones, seguramente, sin una dimensión o anclaje constitucional evidente.

Sorprende, sin duda, la omisión de la libertad de empresa como argumento que justifique la posición de la sentencia. A buen seguro, el Tribunal Constitucional prefiere no establecer una contraposición directa entre un derecho con una tutela privilegiada, la libertad religiosa, y otro que se encuentra fuera de la Sección Primera del Capítulo II de la CE, y que cuenta por tanto con una protección menor.

En puridad, los argumentos que utiliza la sentencia para rechazar esa vertiente activa de la libertad religiosa pueden dividirse en dos grupos. En primer lugar, el Tribunal menciona una serie de razones que seguramente son más propias de un análisis de legalidad ordinaria que de una interpretación del texto constitucional, pero que son valores o principios de necesaria observancia. El encaje constitucional, posiblemente, es el principio de seguridad jurídica, mencionado explícitamente por la sentencia $\left(F J 1^{\circ}\right)$, pero en verdad la argumentación gira en torno a los principios de buena fe y pacta sunt servanda, aunque no aparezcan explicitados de ese modo. Por razones obvias tampoco se menciona en la sentencia, pero sin duda late en toda la argumentación, el art. 1256 CC, a cuyo tenor «la validez y el cumplimiento de los contratos no pueden dejarse al arbitrio de uno de los contratantes». No en vano, la sentencia advierte que un cambio de creencias del trabajador no puede derivar automáticamente en novaciones contractuales para adaptar las exigencias del trabajo al nuevo credo religioso.

En segundo lugar, el otro gran criterio o valor que el Tribunal introduce en su argumentación es el de respeto a las tradiciones. La sentencia rechaza que la fijación del domingo como día de descanso semanal haya venido motivada por la pretensión de impedir que los trabajadores de otras religiones puedan descansar el día que su religión lo exige (situación, desde luego, protegible), y también que el descanso dominical cuente con un propósito exclusivamente religioso. La fijación del domingo como día de descanso semanal es, en último término, un rasgo cultural, una tradición histórica ya consolidada que se ha desligado de la religión católica (aunque su vinculación en origen resulte incuestionable), y que como tal tradición cultural de un país difícilmente puede provocar per se una vulneración de la libertad religiosa, máxime cuando se prevén resortes legales -principalmente el acuerdo- para cambiar ese día de descanso. A la postre, la preferencia por el domingo «facilita mejor el cumplimiento de los objetivos del descanso», pues ese día cierran también oficinas públicas, centros escolares, etc. ( $\left.\mathrm{FJ} 5^{\circ}\right)$.

10. LA RESPUESTA DE LA JURISDICCIÓN ORDINARIA A LA VERTIENTE POSITIVA DE LA LIBERTAD RELIGIOSA

El Tribunal Constitucional sólo ha tenido ocasión de pronunciarse sobre esa vertiente positiva de la libertad religiosa una vez, y por ello conviene hacer una breve referencia a la posición que, hasta el momento, han 
adoptado los tribunales ordinarios. Algunos de los supuestos de hecho son similares al que hubo de resolver la STC 19/1985. Así sucede con la STS de 20-4-1988 (recurso de casación por infracción de ley), en relación con un trabajador, miembro de la Iglesia Adventista del Séptimo Día, que había sido despedido por faltas reiteradas al trabajo, en la medida en que se negaba a prestar servicios los sábados. EI TS acepta y asume la doctrina constitucional, pero puntualiza que en el caso enjuiciado no se había respetado la necesaria proporcionalidad entre falta y sanción, porque el trabajador había sido autorizado por la empresa en un primer momento para cambiar el día de descanso del domingo al sábado. Posteriormente la empresa decidió de manera unilateral reubicar el día de descanso de nuevo en domingo, momento en el que comenzaron a producirse las ausencias. La sentencia no legitima las faltas al trabajo, porque las motivaciones religiosas no pueden imponerse en este caso a las necesidades empresariales, pero estima que esas convicciones atenúan «muy calificadamente las faltas del trabajador, excluyendo para ellas la sanción más grave del mundo laboral como es la de despido». Tampoco aceptan el cambio de día de descanso semanal por imposición del trabajador las SSTSJ de la Comunidad Valenciana de 24-6-1997 (recurso de suplicación 2048/1997) y de 11-9-2000 (recurso de suplicación 1925/2000).

La colisión entre la libertad religiosa y la organización empresarial puede producirse en el terreno de la indumentaria, como sucede en el supuesto que resuelve la STSJ de Baleares de 9-9-2002 (recurso de suplicación 390/2002). El actor prestaba servicios como conductor de autobús para la empresa de transportes municipal, y junto al uniforme utilizaba una gorra con evidente significado religioso -kipá-, pues desde hacía décadas profesaba la religión judía. Tras tolerar esa conducta durante varios años, la empresa decidió imponer a sus trabajadores una completa uniformidad, y prohibió al trabajador portar la kipá en horas de trabajo. La sentencia reconoce inicialmente el derecho de la empresa a exigir la uniformidad, pero advierte que la colisión con un derecho fundamental como la libertad religiosa supone para el empresario la carga de probar un perjuicio que justifique la restricción del derecho del trabajador. Ante la falta de prueba de cualquier trastorno o incidente, y atendiendo además a la naturaleza pública de la entidad empleadora -«puede que, por ello, más comprometida que las de puro carácter privado con el cumplimiento efectivo de los valores constitucionales», afirma la sentencia- el Tribunal acepta las alegaciones del demandante y reconoce su derecho a vestir la kipá durante su jornada laboral.

La negociación colectiva todavía no recoge, al menos con carácter general, reglas específicas para los trabajadores que profesen religiones distintas de la católica, por lo que la ausencia de acuerdo entre empresario y trabajador impide desarrollar esa vertiente positiva o activa de la libertad religiosa, como quedó de manifiesto en la STSJ de Madrid de 27-10-1997 (recurso de suplicación $n^{\circ}$ 2170/1997), donde la actora, musulmana, solicitó 
a su empleador - una cadena de tiendas de conveniencia- no utilizar uniforme con falta corta, la exención de prestar servicios durante tres horas los viernes para efectuar el rezo colectivo, finalizar su jornada una hora antes de la puesta de sol durante el mes de Ramadán y no trabajar en establecimientos donde se manipulasen o vendiesen productos derivados del cerdo y/o alcohol. La empresa denegó todas estas peticiones, decisión respaldada por la sentencia, que si bien reconoce la importancia de la libertad religiosa y la necesidad de compatibilizar las convicciones con el trabajo, considera que es exigible «a la parte trabajadora una conducta especial de lealtad y buena fe, consistente en que -lo que no hizo la actora- al solicitar el puesto de trabajo indique previamente su confesión religiosa y el horario especial que ello implica, a fin de que esa futura empleadora estudie si puede encajar tal situación especial en su infraestructura específica».

En realidad, la vertiente activa de la libertad religiosa -en ese segundo nivel que requiere una acomodación organizativa a las peculiaridades del trabajador- es difícilmente exigible, incluso fuera de la relación laboral. En este sentido, los tres Acuerdos de 1992 reconocen el derecho a solicitar un cambio de día en los exámenes, oposiciones o pruebas selectivas convocadas para el ingreso en las Administraciones Públicas que hayan de celebrarse en uno de los días de descanso o festivos por motivos religiosos, pero admiten que la solicitud puede ser denegada cuando una causa motivada lo impida. Muchas de esas pruebas u oposiciones se realizan en sábado y el llamamiento es único, siendo denegadas las peticiones individuales de cambio de día para garantizar la igualdad de los opositores, justificación que los tribunales vienen estimando suficiente [STSJ (Cont-Adv.) de Aragón de 18-5-1999 (Recurso contencioso-administrativo 187/1996)].

\section{BREVE RESEÑA BIBLIOGRÁFICA}

BARRIOS BAUDOR, G.L., y JIMÉNEZ-AYBAR, I., La conciliación entre la vida laboral y la práctica de la religión musulmana en España. Revista de Trabajo y Seguridad Social, n² 274, 2006.

BLAT GIMENO, F.R., Relaciones laborales en empresas ideológicas. Madrid: Ministerio de Trabajo y Seguridad Social, 1986.

CALVO GALLEGO, F.J., Contrato de trabajo y libertad ideológica. Madrid: Consejo Económico y Social, 1995.

FERNÁNDEZ FERNÁNDEZ, R., TASCÓN LÓPEZ, R., ÁLVAREZ CUESTA, H., y QUIRÓS HIDALGO, J.G., Credo religioso y prestación laboral: ¿ora et labora? Revista de Trabajo y Seguridad Social. $\mathrm{n}^{\circ}$ 284, 2006.

FERNÁNDEZ LÓPEZ, M.F. Libertad ideológica y prestación de servicios. Relaciones laborales: Revista crítica de teoría y práctica. Tomo I, nº 5, 1985.

FERNÁNDEZ MÁRQUEZ, O., Libertad religiosa y trabajo asalariado: condiciones y criterios de articulación. Revista española de derecho del trabajo. nº 133, 2007.

GOÑI SEIN, J.L. El respeto a la esfera privada del trabajador. Madrid: Civitas, 1988.

MARTÍN VALVERDE, A., Libertad religiosa, contrato de trabajo y docencia de religió. Revista española de derecho del trabajo. n 138, 2008. 
PALOMINO LOZANO, R., Objeción de conciencia y relaciones laborales en el Derecho de los Estados Unidos. Revista española de derecho del trabajo. n 50, 1991.

RODRÍGUEZ-PIÑERO Y BRAVO FERRER, M., Libertad ideológica, contrato de trabajo y objeción de conciencia. Relaciones laborales: Revista crítica de teoría y práctica. Tomo II, 2003.

VALDÉS DAL-RÉ, F. Libertad religiosa y contrato de trabajo. in M.E. CASAS BAAMONDE, F. DURÁN LÓPEZ y J. CRUZ VILLALÓN (Coord.). Las transformaciones del Derecho del Trabajo en el marco de la Constitución Española. Madrid: La Ley, 2006. 